are still suffering from "shell shock" and other war neuroses. Not a few pensioners have already applied to the Military Hospitals for relief of ocular symptoms occurring in conjunction with alteration of function of the central nervous system. The symptoms are similar in a very large number of cases.

The following are the most prominent :

1. The patient cannot read print at near range for more than a few moments (or minutes in cases less severely affected) without blurring of the letters. The eftort is accompanied by an aching in the eyes, by headache (frontal) and sometimes by "watering" of the eyes.

2. After gazing at distant objects for a few moments a "mist" comes in front of the eyes. "Objects appear, disappear, appear again."

3. Bright sunlight or artificial light causing aching at the back of and around the eyes. It makes the eyes "water."

4. There are pains (as distinguished from headache) in various parts of the head, more commonly in the temples, radiating beyond the ears to the occipital region. The pain spreads from the occipital region down the neck. It is described as "neuralgic" in character. Almost without exception frontal headache is present.

After having seen a large number of cases with the above symptoms, it is difficult for the ophthalmic surgeon to persuade himself that they are associated with an error of refraction or a pathological want of balance of the ocular muscles. All of these cases are confident that they have not suffered from ocular discomfort before.* Would it not be wise to send all cases of this kind to the neurologist or psychologist? Certainly we must look forward to an extensive organization for dealing with cases of functional diseases of the central nervous system.

\title{
Trachoma and the American Forces
}

At the June meeting of the Ophthalmological Section of the American Medical Association a resolution (proposed by Dr. F. Park Lewis) was adopted, urgently directing the attention of the authorities to the danger of the spread of trachoma through men conscripted for the United States Army, and calling for the exclusion of any found to be infected with the disease. The U.S. Public Health Service has now issued a special statement urging physicians to institute a careful examination for the disease, and to arrange for the treatment of any affected recruits. Meanwhile, the National Committee for the Prevention of Blindness has made

*With the exception of those men who were then suffering from " neurasthenia " in a greater or lesser degree and were taken into the Army. 
enquiries into the prevalence of trachoma in the U.S. Navy during recent years, and has published (The News Letter, October, 1917) the following figures submitted by Surgeon-General W. C. Braisted, of the American Navy :-

$\begin{array}{ccccc}\text { Year. } & & \begin{array}{c}\text { Strength of Navy } \\ \text { and Marine Corps. }\end{array} & & \begin{array}{c}\text { Cases of } \\ \text { Trachoma. }\end{array} \\ 1912 & \ldots & 61,897 & \ldots & 3 \\ 1913 & \ldots & 65,926 & \ldots & 8 \\ 1914 & \ldots & 67,141 & \ldots & 8 \\ 1915 & \ldots & 68,075 & \ldots & 31 \\ 1916 & \ldots & 69,294 & \ldots & 12 \\ & & & \end{array}$

\section{American Ophthalmology and the War}

Major James Bordley, chairman of the sub-committee of ophthalmology of the Council of National Defence, recently outlined to the Clinical Congress of Surgeons of North America, the more important steps taken by his sub-committee with regard to ophthalmology in war. These form interesting reading to the Allies. The sub-committee includes Majors G. E. de Schweinitz, Nelson Miles Black, W. H. Wilmer, Walter R. Parker, and Allen Greenwood. A complete and classified catalogue of all ophthalmologists in America was prepared, and the names of 1,400 men willing and qualified to serve were handed to the Surgeon-General. Of this number more than 300 have been commissioned and upwards of 200 ordered on active duty. The sub-committee has studied the SurgeonGeneral's plans for the organization of the army hospitals, and, where requested, has made suggestions as to the staff and equipment necessary for eye work. A small book has been written ("Ophthalmic Military Surgery, with chapters on Trachoma and Malingering.") The visual requirements for various services of the Army have been considered. The sub-committee of ophthalmology has suggested a glass which possesses a selective absorption of light waves for use in binoculars, field glasses, and range-finders. It has caused to be made for the first time in the United States the soda glass necessary in the manufacture of artificial eyes, heretofore obtained exclusively from Germany. A member of Major Bordley's subcommittee has devised a plan for protecting eyes against injury, believed to be of far-reaching value. The re-education of blind soldiers has not been overlooked. Twelve of the leading authorities on the blind have been called together, so that this complex question may be fully considered. In order to assist the work a patriotic lady has placed her country estate at the disposal of the SurgeonGeneral. Soldiers blinded in the war will be retained in the military service until they have been trained and placed in a suitable trade or profession. Lastly, ophthalmology is to be grouped with 